\title{
Habits of Mathematical Thinking and Development of Heuristics
}

\author{
Su Liang $1 *$ (1)
}

${ }^{1}$ University of Texas at San Antonio, USA

*Corresponding Author: su.liang@utsa.edu

Citation: Liang, S. (2022). Habits of Mathematical Thinking and Development of Heuristics. Contemporary Mathematics and Science Education, 3(1), ep22002. https://doi.org/10.30935/conmaths/11521

\begin{abstract}
Psychological theory indicates that human use heuristics, the psychology of mental shortcuts, to make decisions, solve problems, or learn new knowledge. In this article, I will discuss how some common mathematical mistakes generate from the heuristics process while students learn mathematics or solve mathematics problems, and how we may help students avoid the hurdle of heuristic bias. Constructing heuristics ability of non-linear thinking will be discussed to shed light on teaching students high order of mathematical thinking.

Keywords: heuristics, mathematical thinking, high order of mathematical thinking, reflective thinking, mathematics educator, task design
\end{abstract}

Received: 7 Jul. $2021 \bullet$ Accepted: 5 Jan. 2022

\section{INTRODUCTION}

"Guess, what is the small house for?", my sister who live in Bonn, Germany, asked me to answer the question, after sending me a 6-second video (Figure 1). The small house was in the air supported by the iron frames in the forest where she was hiking. For about one hour, I exhausted all of my knowledge and experience to relate the question through the entire process of thinking. My answer included bird house, tree house for children, bathroom, scenery overview spot, shelter, emergency phone booth, storage for first aid supplies. I ran out of ideas, and did not reach a right answer in the end. The small house is actually an observation platform for hunters, and sometimes hunters also shoot animals from the windows of the small house.

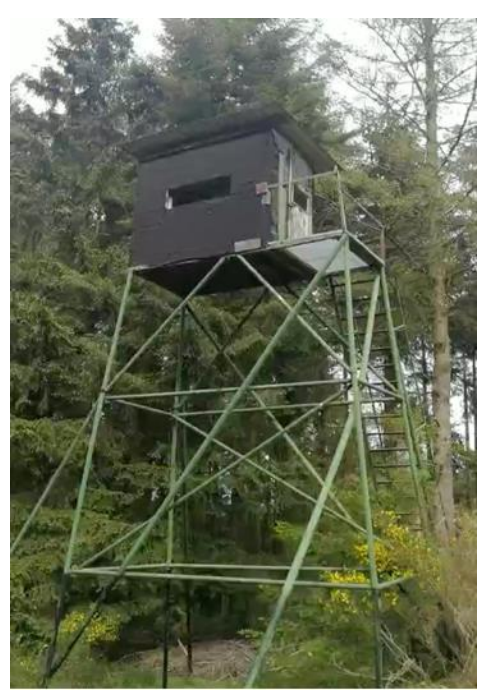

Figure 1. What is the small house for?
Curious about what responses my friends were going to have, I sent the video to 11 friends and asked the same question in a social media group. Just like me, without any experience of hunting, none of them answered correctly. Without a doubt, this is an easy question for a person who often hunts in forest. However, for people like me, it is a very hard question. When I saw the small house, my first response was bird house because I saw a bird house on the top of a tall pole when I hiked in wild places before. All other answers came from my knowledge gained from life experience. Since I never hunt anywhere, the right answer for this question is definitely beyond my imagination.

This event reminds me of mathematics teaching/learning. The thinking process of the small house question is analogous to that of solving a math problem or learning mathematics. When students are given a mathematics problem, they would start with searching the relevant knowledge they are familiar with, which could be a number, a formula, a problem solved before, a life experience that related to the given problem, etc. Psychological theory indicates that human use heuristics, the psychology of mental shortcuts, to make decisions, solve problems, or learn new knowledge. In this article, I will discuss how some common mathematical mistakes generate from the heuristics process while students learn mathematics or solve mathematics problems, and how we may help students avoid the hurdle of heuristic bias. Constructing heuristics ability of non-linear thinking will be discussed to shed light on teaching students high order of mathematical thinking. An example of class activity about Pythagorean theorem will be provided as an example to demonstrate how high-level of mathematical thinking can be facilitated by the intentionally designed activity later in this paper. 


\section{THE LITERATURE AND THE OBSERVATIONS FROM TEACHING PREACTICE}

Heuristics origins from Greek word, meaning "serving to find out or discover” (Gigerenzer \& Gaissmaier, 2011, p. 454). In the literature of mathematics education, Polya (1945) developed a model for students to gain problem-solving skills. His book "How to Solve it" has not only guided mathematics educators to teach mathematical problem solving but also stimulated a significant amount of research on mathematical problem solving. These studies advanced our understanding of heuristics of mathematical problem-solving (Cai, 2010). In the past decades, there have been many research on teaching problem solving and teaching mathematics through problem solving (e.g., Kroll \& Miller, 1993; Lambdin, 2003; Lester \& Cai, 2016; Lester \& Charles, 2003; Liljedah et al., 2016). However, there are still more questions than answers. Many empirical research has developed the consensus that teaching problem solving in mathematics classrooms is promising pedagogy for learning mathematics with understanding. However, few research investigates what role heuristics play in teaching mathematics through problem solving, in what way a class activity can help students to develop heuristics of problem-solving, and how development of heuristics relates to habits of mind and high order of mathematical thinking.

Educational psychology regards heuristics as "rule of thumb" to discover new knowledge or solve uncertainty. Often heuristics could be efficient strategies for humans to make good judgements because less information is used to make the decision but the result may be better than using sophisticated rational methods (Gigerenzer \& Gaissmaier, 2011). However, heuristics could also be error prone when learning mathematics. Some common mathematics mistakes can be made due to different types of heuristics. The examples are provided in the following.

\section{Availability Heuristic}

Availability heuristic tends to assume easily recalled information more important. We prefer to select information more readily available in our memory than those hard to recall. In the event stated in the beginning of the article, I myself and my friends used whatever available information from our life experience to answer the question. Availability heuristic limited us to reach a right answer. Availability heuristic may cause erroneous judgement or decision due to limited knowledge or experience. Tversky and Kahneman (1973) had given an example, life-long experience makes majority of people believe that when tossing a coin there is more probability to have the outcome "HTTHTH" than either "HHHHTH" or "HHHTTT" although the probability of three outcomes is the same, which is $\left(\frac{1}{2}\right)^{6}$. In mathematics learning, availability heuristic may lead to make common mistakes. The one of tossing a coin is just one of many.

\section{Familiarity Heuristic}

We tend to prefer a familiarity as a safe choice than a non-familiar thing. When we are not sure what the answer is for something, we will simply choose whatever is more familiar to us. Teaching preservice teacher content mathematics course for many years, I often see the following mistake:

Given that the edge of square $A$ doubles the edge of square $B$, many students believed that the area of Square $A$ doubles the area of square $B$ and the volume of square $A$ doubles the volume of square $B$ too.

However, the truth is:

Based on the given information, we know that if $b$ is the edge of square $B$, then the edge of square $A$ is $2 b$ and the area of square $A$ is $2 b \times 2 b=4 b^{2}$, but the area of square $B$ is $b \times b=b^{2}$, so the area of square $A$ is 4 times of the area of square $B$; the volume of square $A$ is $2 b \times 2 b \times 2 b=8 b^{3}$ and the volume of square $B$ is $b \times b \times b=b^{3}$, so the volume of square $A$ is 8 times of the volume of square $B$.

In this case, it sounds familiarly making sense that if the edge of one square doubles that of another square, then the area of the square doubles that of another square and the volume of the square doubles that of another square if students don't actually calculate the areas and the volumes.

\section{Fluency Heuristic}

The fluency heuristic is that the easier an idea is to be understood, the more likely it is to be accepted. This means that we tend to choose the easy one if given two options even if the easy answer is wrong, and the difficult answer is right. No wonder why it is not uncommon for mathematics educators to see this way of adding a fraction with different denominators:

$$
\frac{2}{3}+\frac{3}{5}=\frac{5}{8} .
$$

This common error generates when seeing the addition students first recall adding whole numbers but do not easily recall how to add fractions with different denominators. Actually it takes some efforts to convert both fractions into the equivalent fractions with the same unit fractions (finding common denominator) and then add the numerators:

$$
\frac{2}{3}+\frac{3}{5}=\frac{2}{3} \times \frac{5}{5}+\frac{3}{5} \times \frac{3}{3}=\frac{10}{15}+\frac{9}{15}=\frac{19}{15} .
$$

Doing the right way of solving the problem needs to understand the meaning of fractions with different denominators and know how to find common denominator and equivalent fractions, which is more complicated than doing the wrong way which is simply adding denominators and numerators. Although the easy way is wrong, the mistake persists due to its easiness.

\section{Attribute Substitution}

According to Kahneman (2003),

"People are not accustomed to thinking hard, and are often content to trust a plausible judgment that comes to mind." (p. 1450)

When given a relatively difficult problem, most people unconsciously substitute it for an easier problem to solve instead of trying to solve that difficult problem. The process of substitution is attribute substitution heuristic. Kahneman (2011) provided an example. For the following problem:

"A bat and a ball together cost $\$ 1.10$. The bat costs $\$ 1$ more than the ball. How much does the ball cost?"

More than 50\% of students at Harvard, MIT, and Princeton, and over $80 \%$ of students in other universities gave the incorrectly answer " 10 cents". It seems intuitively right but it's wrong, because 
the bat price+the ball price $=\$ 1.10$; given that the bat price $=$ the ball price $+\$ 1$, we can substitute the ball price $+\$ 1$ into the first equation: the bat price + the ball price $=\$ 1.10$, then we reach the following equation: The ball price $+\$ 1+$ the ball price $=\$ 1.1$, Solving equation, we get $2 \times$ (the ball price $)=\$ 0.1$, finally dividing 2 on both sides of the equation, we end up the ball price $=0.05$, so we can conclude that the ball costs $\$ 0.05$.

Using mathematical language to describe the process:

Let $x=$ the bat price and $y=$ the ball price, then $x+y=\$ 1.10$ (given) (Equation 1)

Since $x=y+\$ 1$ (given), we substitute $x=y+\$ 1$ into Equation 1 to get:

$y+\$ 1+y=\$ 1.10$ (Substitution)

$2 y+\$ 1=\$ 1.10$ (Combine the like terms)

$2 y=\$ 0.10$ (isolate the variable)

$y=\$ 0.05$ (divide 2 both sides of the equation and solve for $y$ )

Reflective check: The ball costs 5 cents, the bat costs $\$ 1$ and 5 cents, the bat costs $\$ 1$ more than the ball, and the bat and the ball together cost $\$ 1.10$. The solution is valid.

For people who answered " 10 cents", if they went back to check the given information, they should be able to detect the contradiction: if the ball costs 10 cents, then the bat costs $\$ 1.10$ (given that the bat costs $\$ 1$ more than the ball), following the process, the bat and the ball together cost $\$ 1.20$ instead of the given $\$ 1.10$. This example showed that it is necessary for us to conduct a reflective thinking in addition to the intuitive thinking when solving non-factual problems (factual problems are yes-no type of fact check questions).

These four types of human heuristics discussed above share a common characteristic which is preference for easy or convenient mental thinking process. In mathematics learning, these heuristics may become hurdles for students to learn new concepts/ideas since in most of the times understanding a mathematical idea may not be reached by only a convenient mental process. Although intuitive thinking helps understanding, reflective thinking process needs to be done for validating the intuitive thinking. Reflective thinking involves mathematical reasoning, which is necessary for students to develop and sustain knowledge learned to increase the capacity of their heuristic toolbox. The larger a student's knowledge capacity is available for learning and problem solving, the stronger a student's heuristics ability is at their disposal for high level of cognition.

\section{THEORETICAL FRAMEWORK}

Jean Piaget, a Swiss psychologist, created the learning theory of cognitive and affective development, which has significant impact on mathematics education research and practice, which built a foundation for constructivism. According to constructivism, a learner constructs knowledge by actively engaging in learning, and learning cannot be transferred from a teacher to a passive-listening pupil. Preexisting knowledge is very important for a learner to make connections to new exposed knowledge in the process of actively constructing knowledge. Ausubel (1968) had stated that
"The most important single factor influencing learning is what the learner already knows. Ascertain this, and teach him accordingly." (p. 18)

However, is there a way for a teacher to help students make the connections between new knowledge and prior knowledge? In another word, is there a tool to help students understand the connections through mathematical thinking? Research has indicated that mastery of facts and procedures does not necessarily help development of high order of mathematical thinking (Schoenfeld, 1985). Salomon and Perkins (1998) suggested that the tools of conversation and task help shape the way how students think. Learning takes place during the process of using previously learned knowledge to solve problems (Nunokawa, 2005). The Theory of Didactics situations (TDS) support that well-structured class activity can help students construct new knowledge and make connection between knowledge by engaging them in conducting meaningful mathematical thinking and reasoning (Chevallard \& Bosch, 2020; González-Martín et al., 2014). In an effort of implementing constructivism into mathematics teaching practice, I will demonstrate how a class activity can be designed to help students develop problem-solving heuristics and form a habit of high order of mathematical thinking.

\section{METHOD}

Teaching preservice teacher content course for many years, I have noticed that many of the preservice teachers did not know how to use valid mathematical reasoning to justify what they did because they just conduct a procedure process without understanding the underlying mathematical ideas/concepts. This phenomenon motivates me to search an effective way to address this issue. The research question is then raised: How can we design class activities that facilitate meaningful mathematical understanding? Qualitative method was utilized to conduct the research. The study is based on the existing research in the literature, my observations and reflection on many years of teaching practice at college level, and some data collected from my own classrooms over the years. Data used for analysis are from my classrooms of pre-service teacher content course. Comparative analysis was conducted to find if a design of a class activity is better for facilitating conceptual understanding. In the section followed, the result is discussed and an example is provided and discussed in detail to demonstrate how different ways of engaging students produce different habits of mathematical thinking when learning mathematics and solving problem.

\section{RESULTS AND DISCUSSION}

The article presents to propose that as mathematics educators we should develop class activities that engage students in meaningful mathematical thinking and reasoning. Engaging students in only rote memorizing or procedural learning may shape their habit of linear thinking which can become a hard-removable hurdle in the path of mathematics learning for the long run. Two scenarios are discussed in the following. 
Engaging Students in Meaningful Mathematical Reasoning vs. Engaging Students in Rote Memorizing a Formula

As mathematics educators, we often heard the comment from students: "I know how to do it but I do not know how to explain". However, I observed in most of the cases if students were not able to explain why they did what they did then they did not really understand the mathematical idea involved and they may not know what they say or write represents or means mathematically. For example, in my preservice elementary content courses, often when being asked Pythagorean theorem, some students immediately replied " $a^{2}+b^{2}=$ $c^{2}$, but they were not able to answer the follow-up questions: what do $a, b, c$ represent? Can you explain in what situation this happens? This is a typical example that it does not help mathematics learning if students only memorize mathematical formula without understanding the mathematical meaning. Memorizing something without understanding may become a hurdle for students to either solve problems or learn new knowledge. We see the common mistakes such as applying Pythagorean theorem when a triangle is not right triangle or adding the square of a hypotenuse and the square of a leg to find another leg for a right triangle when solving a problem. These common mistakes were made when students do not understand the meaning of Pythagorean theorem. When teaching Pythagorean theorem, we should explicitly emphasize that it works only for right triangles by providing some examples of acute triangles and obtuse triangles for comparison. Some teachers intends to help students memorize Pythagorean theorem by consistently using " $a^{2}+b^{2}=c^{2}$ ". However the side effect is serious. On the one hand, this make-things-easypractice promotes linear thinking and rote learning. The misunderstanding for Pythagorean theorem may persist and become a hurdle in the future learning path. When teaching this theorem, instead of having students rote memorizing " $a^{2}+b^{2}=c^{2}$ ", we should demonstrate that the hypotenuse could be also represented by $a$ or $b$, the legs of a triangle could be represented by either the pair of $b$ and $c$ or the pair of $a$ and $c$, and the hypotenuse could be represented by $a$ or $b$. Corresponding to the change of representing letters, the Pythagorean theorem can be expressed as $b^{2}+c^{2}=a^{2}$, where $b, c$ are the legs of the triangle and $a$ is the hypotenuse of the triangle or $a^{2}+$ $c^{2}=b^{2}$, where $a, c$ are the legs of the triangle and $b$ is the hypotenuse of the triangle. Furthermore, the legs and the hypotenuse of a right triangle can be represented by any letters, so the Pythagorean theorem can be written as $d^{2}+e^{2}=f^{2}$, where $d, e$ are the legs of the triangle and $f$ is the hypotenuse of the triangle.

Following the explicit demonstration, we should provide a set of different problems to consolidate the understanding:

1. A straightforward question: Given the two legs of a right triangle, find the hypotenuse and provide mathematical reasoning to validate what you did.

2. A non-straightforward question: Given one leg and the hypotenuse of a right triangle, find another leg and provide mathematical reasoning to validate what you did.

3. A backward thinking question: Given three sides of a triangle, determine if the triangle is a right triangle. Please provide mathematical reasoning to validate what you did.

4. Comparing the three problems above, what variations do you observe?

Noticing that the first three questions need to be solved by applying Pythagorean theorem but in different ways. The last question allows students to reflect on what they did and recognize the variations of applying Pythagorean theorem in different situations. Reflective thinking is necessary for us to help students develop heuristics from linear thinking to multi-perspective thinking and avoid error-prone heuristics when either learning mathematics or solving mathematical problems.

Once students thoroughly understand that Pythagorean theorem describes the relationship between the legs and the hypotenuse of a right triangle, the knowledge is added to their heuristic toolbox and is readily available whenever needed in the future; their heuristic level increases accordingly. The common mistakes would be avoided. Only knowing " $a^{2}+b^{2}=c^{2}$ " does not add a readily useful tool in the heuristic toolbox but just put another hurdle on the learning path. How can we help students increase capacity of their heuristic toolbox? Knowledge can be transferred to a student's heuristic toolbox only when it was understood by the student or we can say when the knowledge becomes a "think-able" concept instead of only a "do-able" action (Hegedus, 2010). In order to understand, high order of mathematical thinking needs to frequently present when learning mathematics. The discussion in the next section will focus on how to help students form a habit of high order of mathematical thinking.

\section{Teaching to Shape Studen ts' Habits of Thinking}

When trying to answer a question, we recall related knowledge gained from our life-long experience including learning experience and daily life experience. A factual question (e.g. the small house question in the beginning of the article) involves linear thinking, and a rich life experience will help give a correct answer. However, in mathematics learning, most of the times linear thinking does not help access to understanding but may lead to misunderstanding or setting a hurdle to understand. Educational psychologists discovered that human beings tend to take a shortcut to reach a decision although the shortcut results in a wrong solution (Kahneman, 2003; Tversky \& Kahneman, 1974). The heuristic tendency of taking an easy path can lead to systematic errors. For example, if a student believe that $\frac{2}{3}+\frac{3}{5}=\frac{5}{8}$, this mistake will persist in doing Algebraic operation, showing in this way: $\frac{a}{b}+\frac{a}{c}=\frac{2 a}{b+c}$, which is common to see in a variety of mathematics courses at college level.

When teaching mathematics, we should be aware of the heuristic biases and help students avoid simply straight forward/linear thinking. On the one hand, we should routinely engage students thinking a problem from several perspectives (see the example of teaching Pythagorean theorem discussed above), provide them opportunities to recognize the sameness and difference of relating objects and their properties (Liang, 2021a; Melhuish \& Czocher, 2020), and help them form the habit of multi-perspective thinking; on the other hand, students should be provided ample opportunities to practice reflective thinking when either conducting in-class discussions or doing homework outside classroom because reflective thinking process connects existing knowledge to new information and applying their understanding of background knowledge to new ideas (Liang, 2021b; Van de Walle, 2007). We also have to explicitly let students know that we expect them not only be able to solve a problem but also be able to justify whether their solution is mathematically correct through reflective thinking process (Burns, 2000). Constantly requiring oral or writing explanation of mathematical reasoning can make the reflective thinking become a habit for students to either solve mathematics 
Table 1. Applying the three essentials to design the class activity that facilitates understanding of Pythagorean theorem (PT)

\begin{tabular}{|c|c|c|}
\hline $\begin{array}{l}\text { The three } \\
\text { essentials }\end{array}$ & $\begin{array}{c}\text { Explicitly elucidating the } \\
\text { idea/concept } \\
\& \\
\text { its applying situations }\end{array}$ & $\begin{array}{l}\text { Clearly demonstrating the relationship } \\
\text { between involved quantities/factors/variables }\end{array}$ \\
\hline $\begin{array}{c}\text { The } \\
\text { designed } \\
\text { class } \\
\text { activity }\end{array}$ & $\begin{array}{l}\text { (1). Explicitly elucidates that PT } \\
\text { can only apply to a right triangle. } \\
\text { (2). Explicitly elucidates that in a } \\
\text { right triangle, hypotenuse squared } \\
\text { is equal to the sum of one leg } \\
\text { squared and another leg square. }\end{array}$ & $\begin{array}{l}\text { The legs and hypotenuse of a right triangle can be } \\
\text { represented by any letters. It can be represented as: } \\
\text { (1). } b^{2}+c^{2}=a^{2} \text {, where } b, c \text { are the legs of the } \\
\text { triangle and } a \text { is the hypotenuse of the triangle; } \\
\text { (2). } a^{2}+c^{2}=b^{2} \text {, where } a, c \text { are the legs of the } \\
\text { triangle and } b \text { is the hypotenuse of the triangle; } \\
\text { (3). } d^{2}+e^{2}=f^{2} \text {, where } d, e \text { are the legs of the } \\
\text { triangle and } f \text { is the hypotenuse of the triangle. }\end{array}$ \\
\hline
\end{tabular}

Actively engaging students in solving a variety of problems that involve practicing forward thinking and backward/reflective Provide a set of different problems to consolidate the understanding: (1). A straightforward question: given the two legs of a right triangle, find the hypotenuse and provide mathematical reasoning to validate what you did.

(2). A non-straightforward question: given one leg and the hypotenuse of a right triangle, find another leg and provide mathematical reasoning to validate what you did.

(3). A backward thinking question: given three sides of a triangle, determine if the triangle is a right triangle. Please provide mathematical reasoning to validate what you did.

(4). Comparing the three problems above, what variations do you observe?

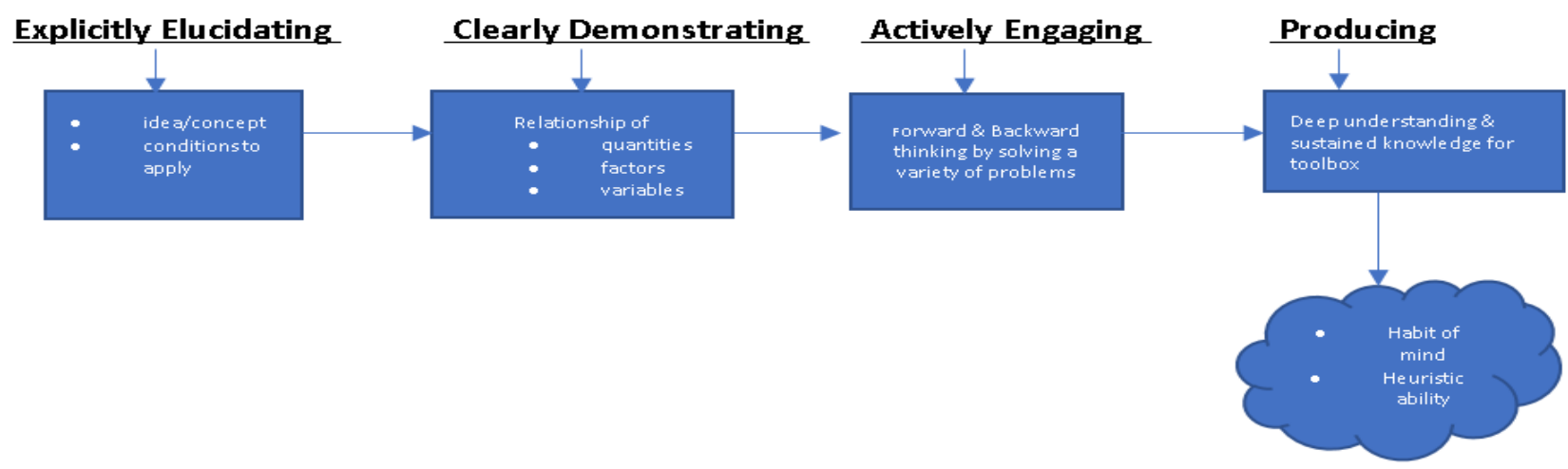

Figure 2. The three essentials for knowledge building

problems or learn new concepts/ideas. In addition, we should encourage students to find alternative ways to solve a problem and compare the thinking process of different solutions at a regular base (Liang, 2021b). Frequent discussions on different ways of solving a problem adds more opportunities for students to get used to thinking from different perspectives. In summary, when designing a class activity for students to understand a mathematical idea, we need to address the three essentials:

1. Explicitly elucidating the idea/concept and its applying situations;

2. Clearly demonstrating the relationship between involved quantities/factors/variables;

3. Actively engaging students in solving a variety of problems that involve practicing forward thinking and backward/reflective thinking.

Using the example of Pythagorean theorem (PT), I created a table to demonstrate how the three essentials were applied when designing the class activity discussed previously (Table 1 ).

The three essentials work together to help sustain newly learned knowledge and increase students' Heuristic ability by adding capacity of their knowledge toolbox. The third essential is the key for students to form a habit of mind of high order of mathematical thinking. Insufficient implementation of the third essential will frame students' vision and thinking in a narrowed and shallowed scope of learning. As a result, an error-prone heuristic is produced to play a dominate role in the path of either learning or problem solving. The diagram in Figure 2 illuminates the three essentials for knowledge building.

\section{CONCLUDING REMARKS}

The three essentials are proposed to construct a teaching-design system that is a promising strategy to facilitate students' deep understanding and high order of mathematical thinking. Implementation of the three essentials was demonstrated in the discussion of teaching Pythagorean theorem. The class activity involving Pythagorean theorem had been implemented but limited to my preservice teacher content courses. Although this is a specific example, the demonstrated process and discussion provided a general framework for mathematics educators to design class activities engaging high order of mathematics thinking and helping development of problem-solving heuristics. Teaching guided by the three essentials may overcome the human nature of error-prone heuristics and avoid linear thinking triggered by rote/procedural mathematical learning. The three essentials will provide ample opportunities for students to think reflectively. As a result, habit of high order of mathematical thinking is promoted and constructed through the process of learning. Future research could focus on how the three essentials can be effectively applied into teaching a certain specific mathematical content and how a teaching plan guided by the three essentials impact students' learning outcomes including habit of mind, problem solving ability, and heuristic development in the long run. In the end, I would like to point out that although the class activity involving Pythagorean theorem showed effective impact on students' mastering Pythagorean theorem based on the assessment results in the end of the semesters, implementation in a larger and a variety of settings is needed to validate the effectiveness of the class activity. 
Funding: The author received no financial support for the research and/or authorship of this article.

Declaration of interest: Author declares no competing interest.

Data availability: Data generated or analysed during this study are available from the authors on request.

\section{REFERENCES}

Ausubel, D. P. (1968). Educational psychology: A cognitive view. Holt, Rinehart \&Winston.

Burns, M. (2000). About teaching mathematics: A K-8 resource. Math Solutions Publications.

Cai, J. (2010). Commentary on problem solving heuristics, affect, and discrete mathematics: A representational discussion. In: B. Sriraman, \& L. English (Eds.), Theories of mathematics education (pp. 251-258). Springer. https://doi.org/10.1007/978-3-642-00742$2 \_25$

Chevallard, Y., \& Bosch, M. (2020). Didactic transposition in mathematics education. In: S. Lerman (Ed.), Encyclopedia of mathematics education. Springer. https://doi.org/10.1007/978-3030-15789-0_48

Gigerenzer, G., \& Gaissmaier, W. (2011). Heuristic decision making. The Annual Review of Psychology, 62, 451-482. https://doi.org/ 10.1146/annurev-psych-120709-145346

González-Martín, A. S., Bloch, I., Durand-Guerrier, V., \& Maschietto M. (2014). Didactic situations and didactical engineering in university mathematics: Cases from the study of calculus and proof. Research in Mathematics Education, 16(2), 117-134. https://doi.org/ 10.1080/14794802.2014.918347

Hegedus, S. J. (2010). Preface to part VI: The fundamental cycle of concept construction underlying various theoretical frameworks by John Pegg and David Tall. In B. Sriraman, \& L. English (Eds.), Theories of mathematics education. Springer.

Kahneman, D. (2003). Maps of bounded rationality: Psychology for behavioral economics. American Economic Review, 93(5), 1449-1475. https://doi.org/10.1257/000282803322655392

Kahneman, D. (2011). Thinking, fast and slow. Farrar, Straus and Giroux.

Kroll, D. L., \& Miller, T. (1993). Insights from research on mathematical problem solving in the middle grades. In D. T. Owens (Ed.), Research ideas for the classroom: Middle grades mathematics (pp. 58-77). National Council of Teachers of Mathematics.
Lambdin, D. (2003). Benefits of teaching through problem solving. In F. Lester (Ed.), Teaching mathematics through problem solving (pp. 314). National Council of Teachers of Mathematics.

Lester, F. K., \& Cai, J. (2016). Can mathematical problem solving be taught? Preliminary answers from 30 years of research. In: P. Felmer, E. Pehkonen, \& J. Kilpatrick (Eds), Posing and solving mathematical problems: Advances and new perspectives. Springer. https://doi.org/10.1007/978-3-319-28023-3_8

Lester, F. K., \& Charles, R. (2003). Teaching mathematics through problem solving:Pre-K-grade 6. National Council of Teachers of Mathematics.

Liang, S. (2021a). Equivalence and substitution: Tools for teaching meaningful mathematics. For the Learning of Mathematics, 41(1), 4143.

Liang, S. (2021b). Deepening mathematics learning by making variation available in teaching. Journal.of Higher Education Theory and Practice, 21(12), 1-9. https://doi.org/10.33423/jhetp.v21i12

Liljedah, P., Trigo, M. S., Malaspina, U., \& Bruder, R. (2016). Problem solving in mathematics education. Springer. https://doi.org/10.1007/ 978-3-319-40730-2

Melhuish, K., \& Czocher, J. A. (2020). Division is pretty much just multiplicationFor the Learning of Mathematics, 40(2), 38-43.

Nunokawa, K. (2005). Mathematical problem solving and learning mathematics: What we expect students to obtain. The Journal of Mathematical Behavior, 24(3-4), 325-340. https://doi.org/10.1016/ j.jmathb.2005.09.002

Polya, G. (1945). How to solve it. Princeton University Press. https://doi.org/10.1515/9781400828678

Salomon, G., \& Perkins, D. N. (1998). Individual and Social Aspects of Learning. Review of Research in Education, 23, 1- 24.

Schoenfeld, A. H. (1985). Mathematical problem solving. Academic Press, INC.

Tversky, A., \& Kahneman, D. (1973). Availability: A heuristic for judging frequency and probability. Cognitive Psychology, 5(2), $207-$ 232. https://doi.org/10.1016/0010-0285(73)90033-9

Tversky, A., \& Kahneman, D. (1974). Judgement under uncertainty: Heuristics and biases. Science, 185(4157), 1124-1131. https://doi.org/10.1126/science.185.4157.1124

Van de Walle, J. A. (2007). Teaching mathematics for understanding. ptgmedia.pearsoncmg.com. http://ptgmedia.pearsoncmg.com/ imprint_downloads/merrill_professional/Van_de_Walle_978013 2824828.pdf 